Gut and Liver, Vol. 11, No. 1, January 2017, pp. 55-61

\title{
Clinical Use of Measuring Trough Levels and Antibodies against Infliximab in Patients with Pediatric Inflammatory Bowel Disease
}

\author{
So Yoon $\mathrm{Choi}^{1}$, Ben Kang ${ }^{1}$, Jee Hyun Lee ${ }^{2}$, and Yon Ho Choe ${ }^{1}$ \\ ${ }^{1}$ Department of Pediatrics, Samsung Medical Center, Sungkyunkwan University School of Medicine, Seoul, and ${ }^{2}$ Department of Pediatrics, \\ Korea University Ansan Hospital, Korea University School of Medicine, Ansan, Korea
}

\section{See editorial on page 3.}

Background/Aims: The clinical use of measuring infliximab (IFX) trough levels (TLs) and antibodies against IFX (ATIs) in patients with pediatric inflammatory bowel disease (IBD) remains unclear. We propose measuring these variables to create individual IFX treatment strategies for patients with pediatric IBD. Methods: This retrospective study was conducted in pediatric patients with IBD who received IFX from July 2009 to June 2014. Results: Samples were available from 39 patients with pediatric IBD. A significant difference was observed in IFX TLs in 16 patients who were in clinical remission (group A) after IFX therapy (median, $3.99 \mu \mathrm{g} /$ $\mathrm{mL}$; interquartile range [IQR], 0.30 to 21.96 ) compared to 23 patients who had a poor response to treatment (group B) (median, $0.88 \mu \mathrm{g} / \mathrm{mL}$; IQR, 0.00 to $6.80, \mathrm{p}=0.002$ ). In group $B, 21$ patients underwent empiric intensification of IFX treatment. After dose intensification, 17 patients had an improved response to treatment. Four patients still had no response to dose intensification. Therefore, these patients were switched to other biologics. Conclusions: Patients who had poor responses and subtherapeutic IFX TLs had an improved response to dose intensification. Patients who had ATIs were likely to continue to have no response after dose intensification. Therefore, tailoring individual IFX treatments based on IFX TLs, ATIs, and the clinical response should be considered. (Gut Liver 2017;11:55-61)

Key Words: Pediatric inflammatory bowel disease; Infliximab; Trough level; Antibodies

\section{INTRODUCTION}

Inflammatory bowel disease (IBD) is currently recognized as one of the most important chronic inflammatory diseases; it affects children and adolescents, and it is characterized by relapsing and remitting episodes. IBD includes Crohn's disease (CD), ulcerative colitis (UC), and inflammatory bowel disease unclassified. Treatment has changed over the past few years, reflecting the development of new agents that can target specific locations in the gastrointestinal tract and specific cytokines. ${ }^{1}$ Infliximab (IFX), a chimeric monoclonal antibody to tumor necrosis factor $\alpha$ (TNF- $\alpha$ ), is effective in patients who have an inadequate response to conventional therapy and in patients who have fistulizing CD. ${ }^{2}$ It is current clinical practice to administer IFX via an intravenous (IV) infusion of $5 \mathrm{mg} / \mathrm{kg}$ at 0 week, 2 weeks, and 6 weeks, followed by maintenance IV infusions every 8 weeks. ${ }^{3}$ Among patients who initially respond to the induction regimen of IFX, the annual risk for loss of response to IFX therapy is 13\% per patient/year. ${ }^{4}$ The mechanisms for the loss of response to IFX are still unclear, and several hypotheses have been proposed, including the presence of antibodies to infliximab (ATIs), a high inflammatory burden of the disease that may consume the drug, or the development of an alternative pathway of inflammation..$^{5-7}$ Empirical management with combination therapy with an immunomodulator, IFX dose escalation, or switching from IFX to another anti-TNF- $\alpha$ drug, mainly adalimumab, is common in clinical practice. ${ }^{8}$ Low serum infliximab trough levels (IFX TLs) have been related to a poor clinical response in IBD. ${ }^{9-11}$ It is important to maintain optimal therapeutic IFX concentrations to sustain the response and achieve good clinical outcomes. Measuring serum IFX TLs and ATIs may predict the course of IFX treatment in individual patients and optimize the

\footnotetext{
Correspondence to: Yon Ho Choe ${ }^{\mathrm{a}}$ and Jee Hyun Lee ${ }^{\mathrm{b}}$

${ }^{a}$ Department of Pediatrics, Samsung Medical Center, Sungkyunkwan University School of Medicine, 81 Irwon-ro, Gangnam-gu, Seoul 06351, Korea Tel: +82-2-3410-3527, Fax: +82-2-3410-0043, E-mail: yonho.choe@samsung.com

${ }^{\mathrm{b}}$ Department of Pediatrics, Korea University Ansan Hospital, 123 Jeokgeum-ro, Danwon-gu, Ansan 15355, Korea

Tel: +82-31-412-7619, Fax: +82-31-405-8591, E-mail: izzihn@gmail.com

Received on January 21, 2016. Revised on March 28, 2016. Accepted on April 4, 2016. Published online September 9, 2016 pISSN 1976-2283 eISSN 2005-1212 https://doi.org/10.5009/gnl16041

@ This is an Open Access article distributed under the terms of the Creative Commons Attribution Non-Commercial License (http://creativecommons.org/licenses/by-nc/4.0) which permits unrestricted non-commercial use, distribution, and reproduction in any medium, provided the original work is properly cited.
} 
dose intensity.

However, the clinical use of measuring IFX TLs and ATIs in regard to the therapeutic decisions for patients with pediatric IBD remains unclear. We propose an individual therapeutic strategy for IFX therapy in patients with pediatric IBD by measuring serum IFX TLs and ATIs.

\section{MATERIALS AND METHODS}

\section{Patients and the study design}

A retrospective analysis was conducted in pediatric patients (aged less than 19 years at diagnosis) with moderate to severe IBD who had received IFX from July 2009 to June 2014 at the Samsung Medical Center. We measured serum IFX TLs and ATIs in patients in whom available blood samples were collected during maintenance treatment and after dose intensification. Exclusion criteria were patients who refused to enter the study, those with indeterminate colitis, patients without any available collected blood samples, those with a follow-up less than 6 months, and primary nonresponders. We analyzed their clinical and laboratory responses according to subsequent management.

First, the relationship between serum IFX TLs and the clinical outcomes was evaluated. Enrolled patients were divided into two groups according to their clinical response. Group A included patients who achieved clinical remission with conventional IFX therapy, and group B included patients with a poor response to IFX therapy. All patients were treated with IFX via an IV infusion of $5 \mathrm{mg} / \mathrm{kg}$ at 0 week, 2 weeks, and 6 weeks, followed by maintenance IV infusions every 8 weeks for more than 1 year. Patients were naïve to previous TNF-blocking therapy. We measured IFX TLs and ATIs by using blood samples that had been collected just before the infusion of IFX during maintenance treatment within a year from starting IFX, and we compared patients' clinical and laboratory data by using their medical records.

Second, we evaluated the change in serum IFX TLs after dose intensification and the correlation between IFX TLs and the clinical response. Patients who lost their response to conventional IFX treatment underwent a dose intensification of IFX. Adjustments of the infusion interval to 4 or 6 weeks and/or an increment in the dose of $10 \mathrm{mg} / \mathrm{kg}$ IFX were performed at the discretion of the treating physician (Fig. 1). The treating physician was blinded to the results of IFX TLs and ATIs. We also divided patients into those who regained the response and those with a poor response after dose intensification. According to subsequent management, IFX TLs of patients who regained the response after an intensified dose infusion were compared to those of patients with a poor response.

\section{Definitions}

Clinical remission was defined as a symptom-free state throughout the 1-year follow-up period. A Pediatric Crohn's Disease Activity Index score ${ }^{12}$ or Pediatric Ulcerative Colitis Activity Index score ${ }^{13}<10$ was used to define remission. Maintenance treatment was defined as at least one 8-week interval infusion of IFX after the induction course prior to any dose intensification. Dose intensification was defined as either an increase in the IFX dose, a decrease in the interval, or both. A regained response to the intensification dose was defined as an improvement in symptoms at the first clinic visit after dose intensification of IFX per the treating physician's judgment, coupled with a decision to continue the intensified dose regimen

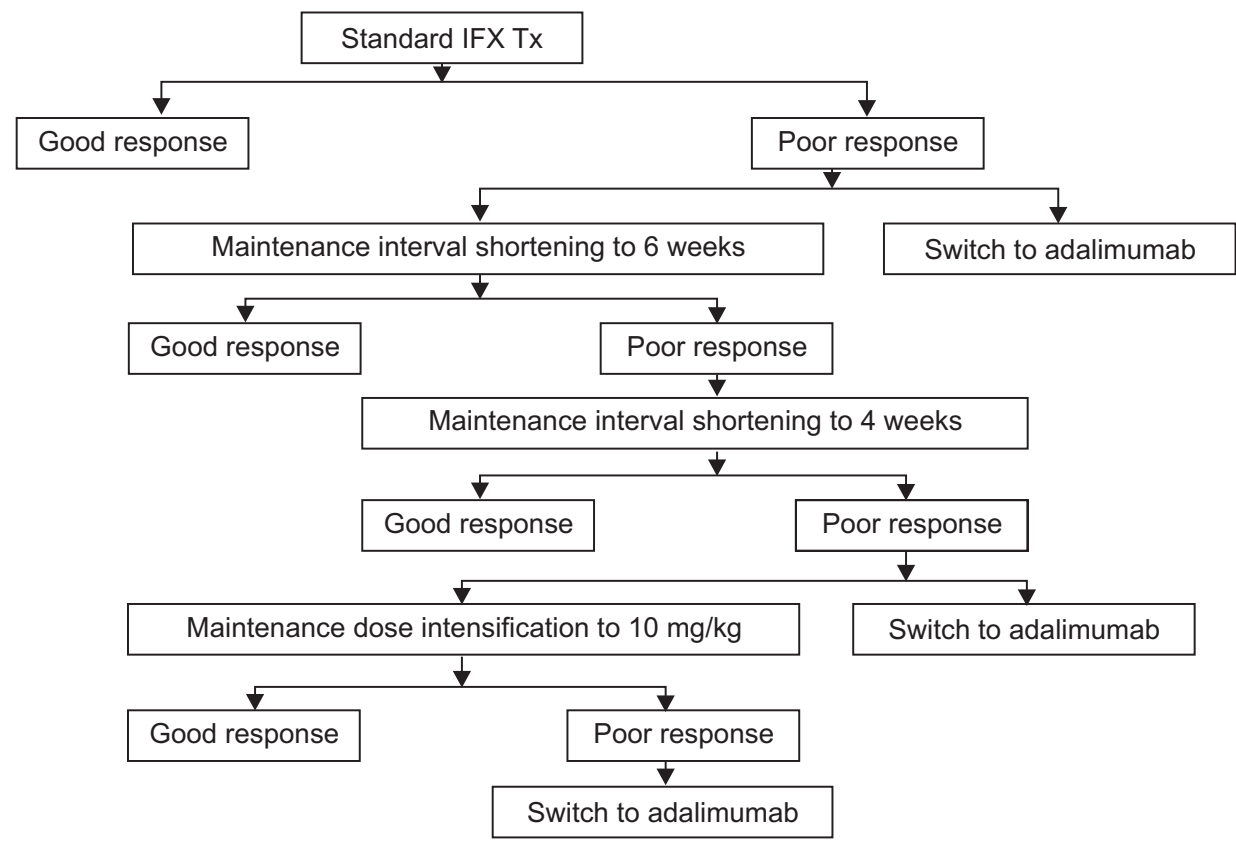

Fig. 1. The blind escalation treatment protocol of the Samsung Medical Center.

IFX Tx, infliximab treatment. 
without adjustments. A poor response after dose intensification was defined by the absence of improvement in disease symptoms.

\section{Serum testing}

Serum samples were collected just before each IFX infusion from patients treated with IFX therapy and then stored at $-20^{\circ} \mathrm{C}$. Serum IFX TLs and ATIs were determined in duplicate by enzyme-linked immunosorbent assay (ELISA) in a blinded fashion with Q-INFLIXI ELISA quantitative analyses (Matriks Biotek, Ankara, Turkey) and Q-ATI ELISA quantitative analyses (Matriks Biotek).

\section{Statistical analysis}

Descriptive statistics are presented as medians and interquartile ranges (IQRs). Fisher exact test and the chi-square test were used to compare variables between the groups, and the $p$-value for statistical significance was defined as $p<0.05$. Effects of the IFX dose intensification (from 5 to $10 \mathrm{mg} / \mathrm{kg}$ ) and shortening the administration interval for serum IFX TLs were analyzed by Wilcoxon rank sum test. Statistical analysis was performed by using SAS version 9.4, statistical package for Microsoft Windows (SAS Institute Inc., Cary, NC, USA).

\section{RESULTS}

\section{Serum IFX TLs and ATIs between patients with clinical remission and those with a poor response}

During the study period, we obtained 99 IFX TLs measurements from 39 patients (10 with UC, 29 with CD). One to eight samples were available per patient (median, two samples). We could measure IFX TLs and the presence of ATIs (Fig. 2). This study included 26 men (67\%) and 13 women (33\%). All patients were treated with azathioprine $(0.5$ to $1 \mathrm{mg} / \mathrm{kg} /$ day) and mesalazine (50 mg/kg/day) concomitantly with IFX. Sixteen patients (three with UC and 13 with $\mathrm{CD}$ ) were in clinical remission (group A), and 23 (seven with UC and 16 with $\mathrm{CD}$ ) had a poor response (group B) to conventional IFX treatment. The demographics and disease characteristics of patients were similar between the two groups (Table 1), and there were no differences in terms of sex, age, and the disease duration. In groups A and B, the serum IFX TLs were performed once per patient during maintenance treatment within a year after starting IFX. There was a significant difference in IFX TLs in patients with clinical remission (group A) (median, $3.99 \mu \mathrm{g} / \mathrm{mL}$; IQR, 0.30 to 21.96 ) after IFX treatment compared with patients who had a poor response (group B) (median, $0.88 \mu \mathrm{g} / \mathrm{mL}$; IQR, 0.00 to 6.80, p=0.002) (Fig. 3). Serum IFX TLs correlated with the clinical outcomes. Correlation coefficients between IFX TLs and the erythrocyte sedimentation rate, C-reactive protein, and albumin were $-0.10(\mathrm{p}=0.670),-0.07$ $(p=0.775)$, and $0.35(p=0.124)$, respectively; none were statistically significant. Seven patients had ATIs in group B, whereas no patient had ATIs in group A.

\section{Serum IFX TLs and ATIs after dose intensification in patients with a poor response}

In group B, 21 patients (seven with UC and 14 with $\mathrm{CD}$ ) empirically underwent an intensification dose of IFX treatment, and two with $\mathrm{CD}$ needed to be switched to adalimumab because of adverse reactions to IFX. Two patients in whom the serum IFX TLs were $0 \mu \mathrm{g} / \mathrm{mL}$ and the ATIs were positive needed to be switched to adalimumab. The duration from IFX initiation to the loss of a response was 18 to 48 weeks (median, 30 weeks). The median time from baseline to the dose intensification was 16 months. The median time from dose intensification to measuring serum IFX TLs was 3 months. After dose intensification, the serum IFX TLs were measured retrospectively in 81 samples of 21 patients (median, three samples per patient). Seventeen patients $(17 / 21,80.9 \%)$ regained the response, and their IFX TLs were increased (median, $7.76 \mu \mathrm{g} / \mathrm{mL}$; IQR, 1.96 to

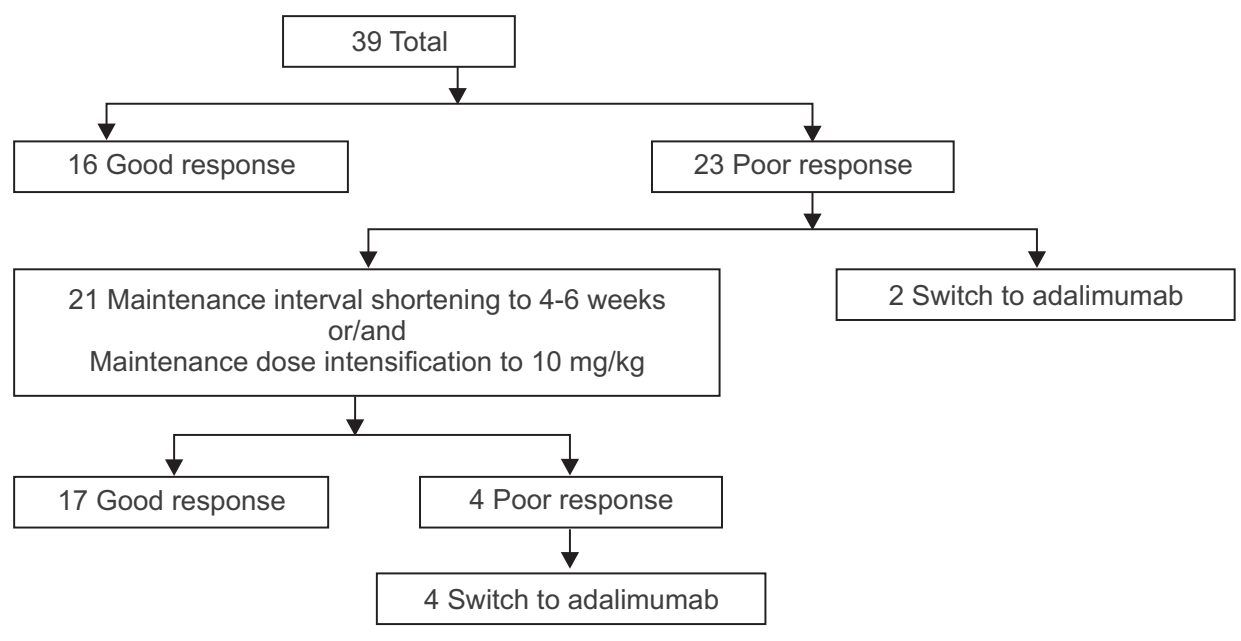

Fig. 2. Enrollment and treatment of patients by group based on the algorithm presented in Fig. 1. 
Table 1. Baseline Characteristics at Baseline Infliximab $(n=39)$

\begin{tabular}{|c|c|c|c|}
\hline Characteristic & Group A $(n=16)$ & Group B $(n=23)$ & p-value \\
\hline Male sex & $12(75)$ & $14(61)$ & 0.4946 \\
\hline Crohn's disease & $13(81)$ & $16(70)$ & 0.4798 \\
\hline \multicolumn{4}{|l|}{ Location of disease } \\
\hline Lower GI location & & & 0.6322 \\
\hline L1 & 0 & 0 & \\
\hline L2 & $3(23)$ & $2(12.5)$ & \\
\hline L3 & $10(77)$ & $14(87.5)$ & \\
\hline Upper GI location & & & 0.7194 \\
\hline No involvement & $9(69)$ & $12(75)$ & \\
\hline L4a & $3(23)$ & $2(12.5)$ & \\
\hline L4b & $1(8)$ & $2(12.5)$ & \\
\hline $\mathrm{L} 4 \mathrm{a}+\mathrm{b}$ & 0 & 0 & \\
\hline Perianal fistulas & $10(77)$ & $14(87.5)$ & 0.6322 \\
\hline PCDAI at IFX & $32.5(17.5-55.0)$ & $31.3(12.5-60.0)$ & 0.8259 \\
\hline Ulcerative colitis & $3(19)$ & $7(30)$ & 0.4798 \\
\hline Location of disease & & & 1.0000 \\
\hline E3 & 0 & $2(29)$ & \\
\hline E4 & $3(100)$ & $5(71)$ & \\
\hline PUCAI at IFX & $65(55-70)$ & $50(35-65)$ & NA \\
\hline Age at diagnosis, yr & $14.5(10.0-17.4)$ & $14.0(7.4-18.5)$ & 0.3376 \\
\hline Age at IFX, yr & $14.7(13.3-17.5)$ & $14.8(9.0-18.8)$ & 0.7123 \\
\hline Duration from diagnosis to IFX infusion, mo & $3(0.5-48)$ & $8(0.2-37)$ & 0.4669 \\
\hline Concomitant IMM at start IFX & $16(100)$ & $23(100)$ & NA \\
\hline Concomitant mesalazine at start IFX & $16(100)$ & $23(100)$ & NA \\
\hline Corticosteroid use prior to IFX & $4(25)$ & $13(57)$ & 0.0994 \\
\hline Hematocrit, \% & $37.0(28.3-44.3)$ & $33.8(26.0-44.2)$ & 0.1058 \\
\hline Albumin, $\mathrm{g} / \mathrm{dL}$ & $4.0(2.8-4.6)$ & $3.7(2.3-4.5)$ & 0.3295 \\
\hline $\mathrm{ESR}, \mathrm{mm} / \mathrm{hr}$ & $50(6-106)$ & $54(21-99)$ & 0.5522 \\
\hline C-reactive protein, $\mathrm{mg} / \mathrm{dL}$ & $1.14(0.04-7.51)$ & $0.76(0.05-7.12)$ & 0.9209 \\
\hline
\end{tabular}

Data are presented as number (\%) or median (interquartile range).

L1, distal 1/3 ileum \pm limited cecal disease; L2, colonic disease; L3, ileocolonic disease; L4a, upper disease proximal to the ligament of Treitz; L4b, upper disease distal to the ligament of Treitz and proximal to the distal 1/3 ileum; L4a+b, upper disease involvement in both L4a and L4b; E3, extensive (hepatic flexure distally); E4, pancolitis (proximal to the hepatic flexure).

IFX, infliximab; GI, gastrointestinal; PCDAI, pediatric Crohn's disease activity index; PUCAI, pediatric ulcerative colitis activity index; NA, not available; IMM, immunomodulator; ESR, erythrocyte sedimentation rate.

20.00) (Figs. 4 and 5). One of them who had ATIs regained the response, and then his ATIs disappeared. Four patients still had no response to dose intensification; their IFX TLs $(0.0 \mu \mathrm{g} / \mathrm{mL})$ were not increased after dose intensification, and all of them had ATIs. They had not regained the response after we repeatedly attempted to decrease the interval and increase the dose. Thus, they needed to be switched to another anti-TNF agent, i.e., adalimumab.

\section{DISCUSSION}

This is the first study to investigate IFX TLs and ATIs in pe- diatric patients with IBD in Korea. In long-term follow-up and clinical trial studies, many patients who initially achieved remission with IFX subsequently experienced a reduced response over time. ${ }^{4}$ In the a Crohn's disease clinical trial evaluating infliximab in a new long-term treatment regimen I study, an increase in IFX to $10 \mathrm{mg} / \mathrm{kg}$ in patients with luminal CD restored the response in $90 \%$ of patients who lost the response after receiving $5 \mathrm{mg} / \mathrm{kg}$ of IFX. ${ }^{14}$ In pediatric $\mathrm{CD}$, almost every other primary responder will require a dose escalation within the first year of therapy. ${ }^{15-17}$ In pediatric patients, the pharmacokinetics of IFX have been associated with weight instead of age. ${ }^{18}$ Therefore, the drug dose needs to be adjusted according to the 


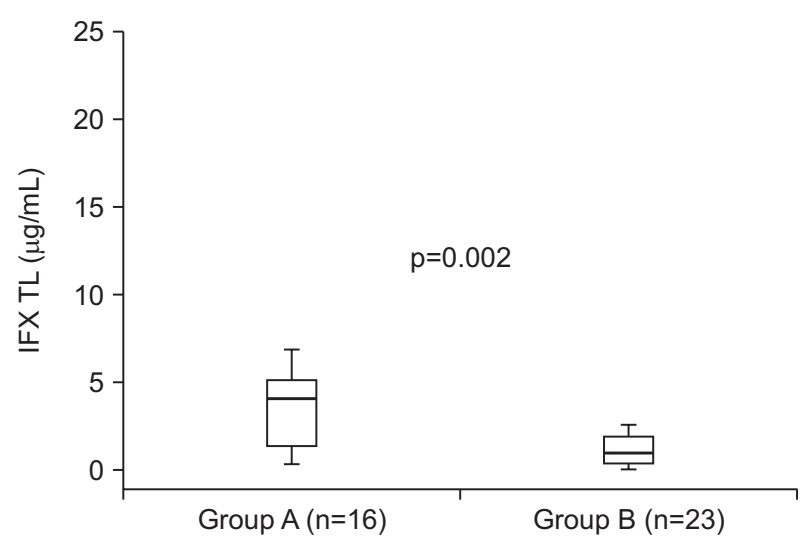

Fig. 3. Comparison of infliximab trough levels (IFX TLs) during maintenance IFX therapy in patients with complete remission (group A) and in patients with a poor treatment response (group B) $(\mathrm{p}=0.002)$.

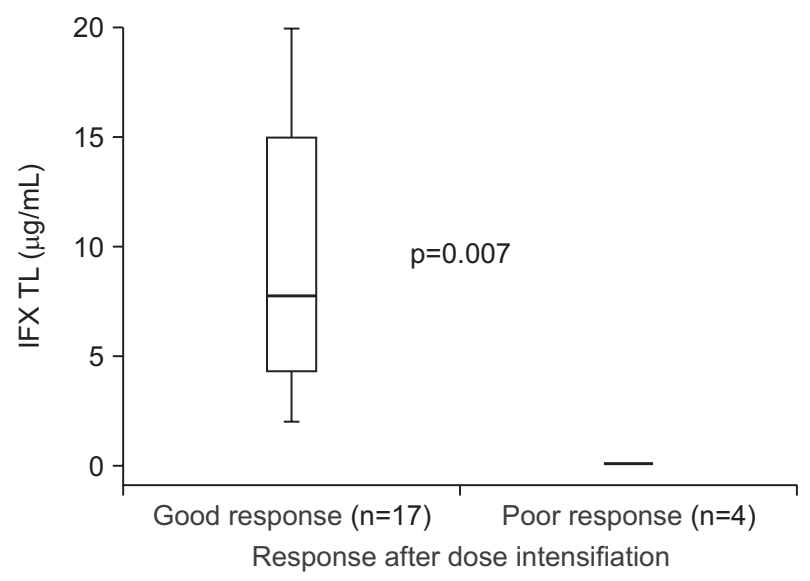

Fig. 4. Comparison of infliximab trough levels (IFX TLs) after dose intensification based on the clinical response $(\mathrm{p}=0.007)$.

patient's individual characteristics.

Maser et al. ${ }^{10}$ evaluated the link between IFX TLs and the clinical outcome in a consecutive cohort of patients with CD $(n=82)$ treated with scheduled IFX. The rate of clinical remission was significantly higher in patients with detectable IFX TLs compared to those with undetectable IFX TLs (82\% vs 6\%). This association was also observed in UC, as Seow et al. ${ }^{11}$ found that detectable IFX TLs were associated with higher rates of remission (69\% vs 15\%) in a cohort of 115 patients. In our study, the serum IFX TLs of patients with clinical remission were higher than those in patients with a poor response. The results were statistically significantly different between the two groups. Thus, it is important to measure IFX TLs before every infusion and maintain therapeutic IFX TLs to achieve clinical remission.

Rutgeerts et al. ${ }^{19}$ showed that restoration of the response in patients with CD after loss of the response and subsequent dose intensifications was associated with an increase in IFX TLs compared with patients in which the dose intensification was unsuccessful. In our study, 17 patients regained the response

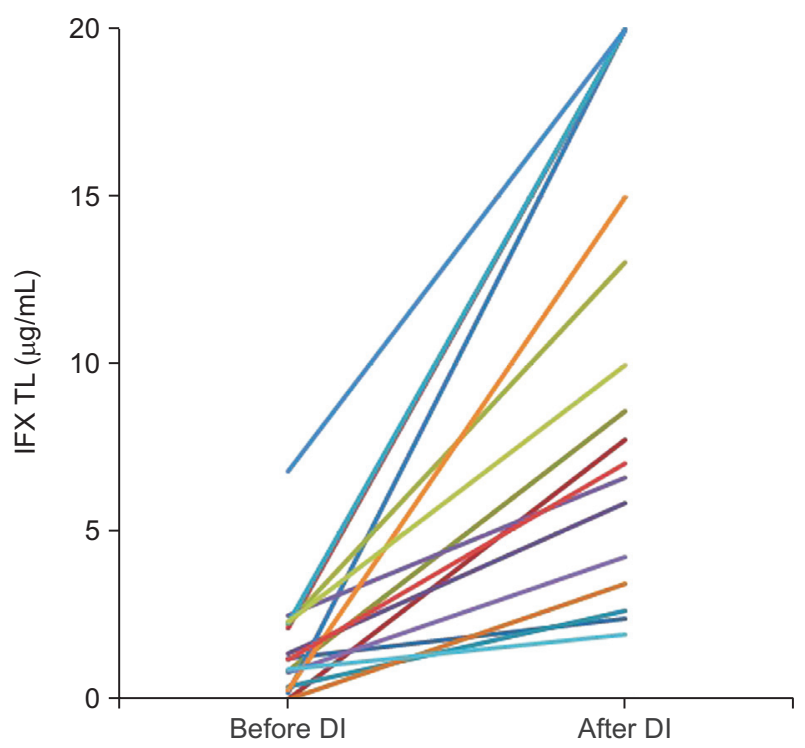

Fig. 5. The change in infliximab trough levels (IFX TLs) for each patient who had a good treatment response to dose intensification (DI).

after dose intensification, and their IFX TLs increased dramatically. Patients who had a loss of response can regain a clinical response by dose intensification of IFX. However, the IFX TLs of patients who had a poor response were still low and all of them had ATIs. Thus, they needed to be switched to another biologic. The presence of ATIs is associated with a significantly higher risk of loss of clinical response to IFX and lower serum IFX levels in patients with IBD. ${ }^{20}$ The rate of developing ATIs in our study was similar to that reported for adult patients. In our study, one patient's ATIs became undetectable after IFX dose intensification. They were transient ATIs. ${ }^{21}$ Transient ATIs can disappear after dose intensification, and the patient can regain a clinical response.

Based on the algorithm proposed by Afif et al., ${ }^{22}$ patients with IFX TLs within the therapeutic range $(<1.4 \mu \mathrm{g} / \mathrm{mL})$ and no detectable ATIs should undergo intensification of IFX treatment, whereas patients with IFX TLs within the therapeutic range $(>1.4 \mu \mathrm{g} / \mathrm{mL})$ and with active disease should be switched to a non-anti-TNF agent. ${ }^{23}$ According to the same proposed algorithm, switching to another anti-TNF agent is recommended as the best therapeutic option in patients who develop ATIs. In Denmark, Steenholdt et al. ${ }^{24}$ concluded that individualized IFX therapy, based on drug levels, was more cost-effective than empirical dose intensification in patients who lost the response to IFX. Measuring IFX TLs and ATIs by using an ELISA assay, and appropriate adjustments to the treatment regimen according to the response have been used in medical practice to optimize clinical outcomes. ${ }^{22}$ A number of cohort studies have reported that these escalation strategies can help regain the response in up to $80 \%$ of patients who have lost the response. ${ }^{22}$ Our results showed that an individual IFX treatment strategy is effective in 


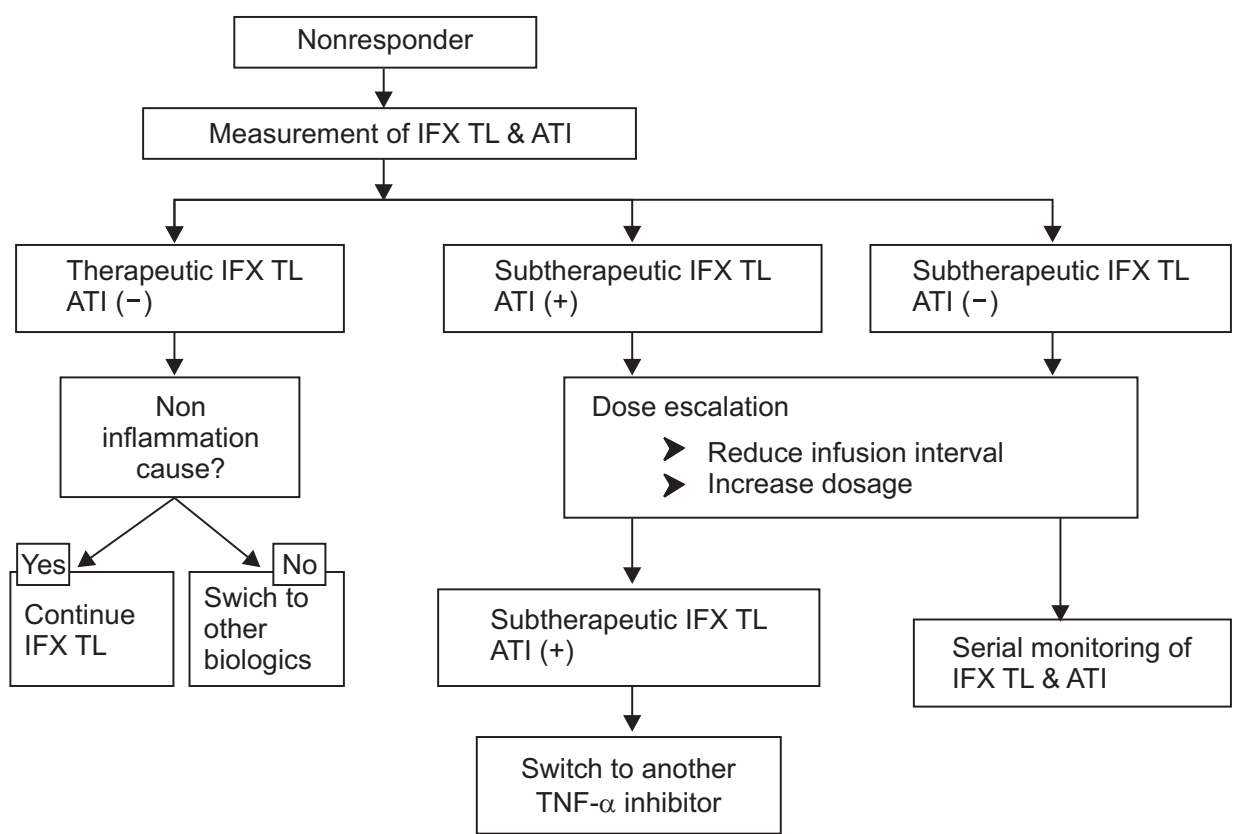

Fig. 6. New protocol of the Samsung Medical Center for treating nonresponders.

IFX TL, infliximab trough level; ATI, antibody to infliximab; IFX Tx, infliximab treatment; TNF- $\alpha$, tumor necrosis factor $\alpha$. pediatric patients who have lost the response despite using conventional therapy. Our pediatric patients who received a dose escalation or shortened interval treatment had no complications during the follow-up period. Thus, individual IFX treatment can be performed safely in pediatric patients.

Limitations of the study were the relatively small sample size and lack of data on the efficacy of the long-term follow-up. We only assessed the response to intensification of IFX therapy over a short period. Additionally, our data were obtained from patients whose blood samples were available under the blind escalation protocol before 2014. Since 2014, we have been conducting a prospective study with our new protocol (Fig. 6). Prospective follow-up studies with larger patient data sets are needed to determine cutoff trough levels for IFX that are associated with a clinical response in pediatric patients with IBD.

When patients have a poor response to IFX therapy, physicians should measure serum IFX TLs and the presence of ATIs. Patients who have poor responses and subtherapeutic IFX TLs can regain the response after dose intensification. Patients who have ATIs are likely to have no response after dose intensification; however, in our study one patient regained the response after dose intensification and his ATIs disappeared. Thus, ATIs can be transient. Therefore, an individual IFX treatment according to the results of IFX TLs, ATIs, and the clinical response should be considered.

\section{CONFLICTS OF INTEREST}

No potential conflict of interest relevant to this article was reported.

\section{REFERENCES}

1. Bosani M, Ardizzone S, Porro GB. Biologic targeting in the treatment of inflammatory bowel diseases. Biologics 2009;3:77-97.

2. Rutgeerts P, D’Haens G, Targan S, et al. Efficacy and safety of retreatment with anti-tumor necrosis factor antibody (infliximab) to maintain remission in Crohn's disease. Gastroenterology 1999;117:761-769.

3. Hyams J, Crandall W, Kugathasan S, et al. Induction and maintenance infliximab therapy for the treatment of moderate-to-severe Crohn's disease in children. Gastroenterology 2007;132:863-873.

4. Gisbert JP, Panés J. Loss of response and requirement of infliximab dose intensification in Crohn's disease: a review. Am J Gastroenterol 2009;104:760-767.

5. Ben-Horin S, Chowers Y. Review article: loss of response to antiTNF treatments in Crohn's disease. Aliment Pharmacol Ther 2011;33:987-995.

6. Matsuoka K, Kanai T. Mechanism and therapeutic strategy of secondary failure to anti-tumor necrosis factor-alpha monoclonal antibody treatment for Crohn's disease. Digestion 2013;88:17-19.

7. Scott FI, Lichtenstein GR. Therapeutic drug monitoring of antiTNF therapy in inflammatory bowel disease. Curr Treat Options Gastroenterol 2014;12:59-75.

8. Guerra I, Bermejo F. Management of inflammatory bowel disease in poor responders to infliximab. Clin Exp Gastroenterol 2014;7:359-367.

9. Baert F, Noman M, Vermeire S, et al. Influence of immunogenicity on the long-term efficacy of infliximab in Crohn's disease. N Engl J Med 2003;348:601-608.

10. Maser EA, Villela R, Silverberg MS, Greenberg GR. Association of serum infliximab to clinical outcome after scheduled maintenance treatment for Crohn's disease. Clin Gastroenterol Hepatol 
2006;4:1248-1254.

11. Seow CH, Newman A, Irwin SP, Steinhart AH, Silverberg MS, Greenberg GR. Trough serum infliximab: a predictive factor of clinical outcome for infliximab treatment in acute ulcerative colitis. Gut 2010;59:49-54.

12. Hyams JS, Ferry GD, Mandel FS, et al. Development and validation of a pediatric Crohn's disease activity index. J Pediatr Gastroenterol Nutr 1991;12:439-447.

13. Turner D, Travis SP, Griffiths AM, et al. Consensus for managing acute severe ulcerative colitis in children: a systematic review and joint statement from ECCO, ESPGHAN, and the Porto IBD Working Group of ESPGHAN. Am J Gastroenterol 2011;106:574-588.

14. Hanauer SB, Feagan BG, Lichtenstein GR, et al. Maintenance infliximab for Crohn's disease: the ACCENT I randomised trial. Lancet 2002;359:1541-1549.

15. de Ridder L, Rings EH, Damen GM, et al. Infliximab dependency in pediatric Crohn's disease: long-term follow-up of an unselected cohort. Inflamm Bowel Dis 2008;14:353-358.

16. Hyams JS, Lerer T, Griffiths A, et al. Long-term outcome of maintenance infliximab therapy in children with Crohn's disease. Inflamm Bowel Dis 2009;15:816-822.

17. De Bie CI, Hummel TZ, Kindermann A, et al. The duration of effect of infliximab maintenance treatment in paediatric Crohn's disease is limited. Aliment Pharmacol Ther 2011;33:243-250.
18. Klotz U, Teml A, Schwab M. Clinical pharmacokinetics and use of infliximab. Clin Pharmacokinet 2007;46:645-660.

19. Rutgeerts P, Van Assche G, Vermeire S. Optimizing anti-TNF treatment in inflammatory bowel disease. Gastroenterology 2004;126:1593-610.

20. Nanda KS, Cheifetz AS, Moss AC. Impact of antibodies to infliximab on clinical outcomes and serum infliximab levels in patients with inflammatory bowel disease (IBD): a meta-analysis. Am J Gastroenterol 2013;108:40-47.

21. Vande Casteele N, Gils A, Singh S, et al. Antibody response to infliximab and its impact on pharmacokinetics can be transient. Am J Gastroenterol 2013;108:962-971.

22. Afif W, Loftus EV Jr, Faubion WA, et al. Clinical utility of measuring infliximab and human anti-chimeric antibody concentrations in patients with inflammatory bowel disease. Am J Gastroenterol 2010;105:1133-1139.

23. Steenholdt C, Bendtzen K, Brynskov J, Thomsen 0Ø, Ainsworth MA. Cut-off levels and diagnostic accuracy of infliximab trough levels and anti-infliximab antibodies in Crohn's disease. Scand J Gastroenterol 2011;46:310-318.

24. Steenholdt C, Brynskov J, Thomsen 0Ø, et al. Individualised therapy is more cost-effective than dose intensification in patients with Crohn's disease who lose response to anti-TNF treatment: a randomised, controlled trial. Gut 2014;63:919-927. 